\title{
Fisiologia da acomodação e presbiopia
}

\author{
Physiologyof Accommodation and Presbyopia
}

Leonardo Werner

Fernando Trindade

Frederico Pereira

Liliana Werner

\section{RESUMO}

A presbiopia é um dos mais precoces sinais do envelhecimento natural e a fisiopatologia básica envolvida no seu desenvolvimento tem sido um tema de controvérsia durante séculos. Este artigo discute vários aspectos da presbiopia através de uma revisão literária das alterações que ocorrem no olho durante este processo, e que já foram descritas previamente por diversos autores.

Palavras-chave: Acomodação; Presbiopia.

\section{O Mecanismo de Acomodação}

Ao se estudar o mecanismo básico da acomodação e presbiopia tornase fundamental entender a fisiologia do olho. $\mathrm{O}$ olho normal jovem pode facilmente focalizar de perto e de longe os objetos, isto é, ele pode alterar o foco ou acomodar. A palavra "acomodação" tem um origem relativamente recente e foi definitivamente introduzida por Burow em $1841^{1,2}$. Alguns livros antes desta data usavam o termo "adaptação", hoje aceito como relativo às variações da sensibilidade retiniana devido as mudanças na intensidade luminosa. Explicações de como a acomodação ocorre têm sido propostas desde longa data. Em uma revisão de literatura sobre acomodação e presbiopia veremos que muito do que se assume ser conhecido é ainda controverso. Se a inervação responsável pela acomodação não está bem caracterizada, também o mecanismo de desenvolvimento da presbiopia é de certo modo teórico. Cientistas têm estudado as alterações da habilidade dos olhos em focalizar (amplitude de acomodação) em relação a idade. Os resultados indicam que a amplitude de acomodação diminui de maneira linear com a idade e este declínio ocorre de maneira universal e previsível (Fig. 1). Se o paciente está propriamente corrigido para distância, sua idade pode ser calculada com uma variação de um ano e meio, medindo-se sua amplitude de acomodação. Sendo assim, uma teoria adequada do mecanismo de acomodação e presbiopia deve levar em consideração as alterações observáveis no olho durante o esforço de acomodação, além de prover uma explicação razoável para o seu declínio em função da idade. Em vista do grande número de teorias propostas desde longa data, nós encontramos que o mecanismo e as inter-relações destas teorias não estão complemente esclarecidos e alguns estudos têm sido conduzidos no sentido de prover um entendimento mais acurado da acomodação e presbiopia.

O reflexo de acomodação é modulado comumente como um sistema "feedback" que opera de maneira a aumentar ou otimizar o contraste luminoso da imagem retiniana. Quando a fixação muda de um alvo longe para perto, cada olho acomoda e ambos convergem no interesse de manter a visão binocular. $O$ caráter desta mudança, as variáveis que a afetam, bem como os mecanismos através do qual isto pode ser alterado não pararam de 


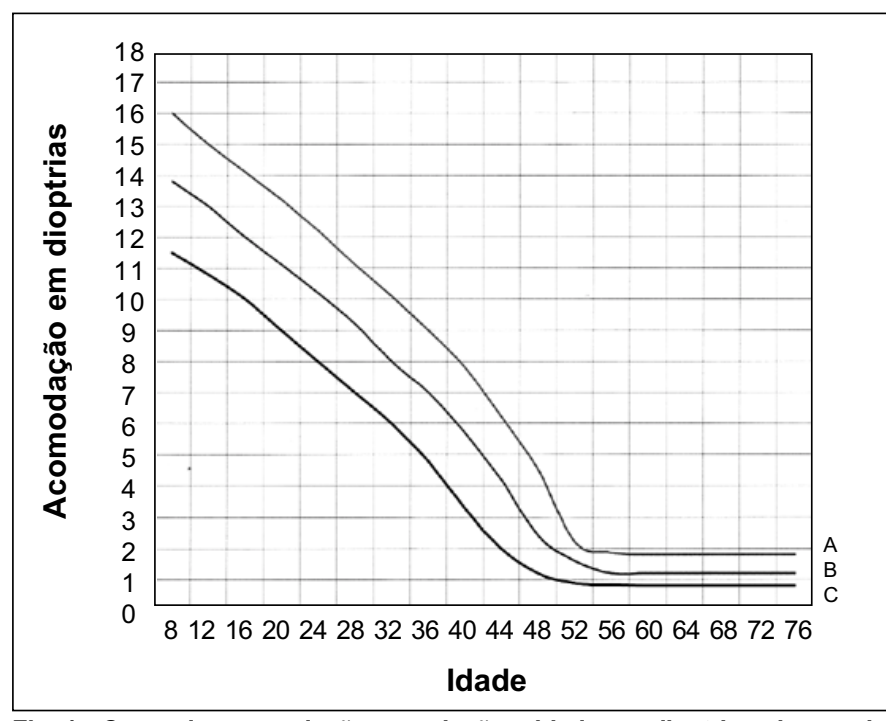

Fig. 1 - Curva da acomodação em relação a idade em dioptrias, de acordo com Duane ${ }^{33}$. (A: valores mínimos; B: valores médios; C: valores máximos).

despertar interesse. Historicamente, a existência de um mecanismo acomodativo foi primeiramente demonstrada por Scheiner (1619). No seu experimento, feito em um cartão onde objetos são vistos a um distância variável através de furos contidos no mesmo, ele provou que no olho existe um mecanismo controlando o ajuste de foco (Fig. 2). Entretanto, a verdadeira explicação para este experimento clássico foi oferecida por William Porterfield (1759), que sugeriu ser a acomodação conseqüência de mudanças no cristalino. Outras possíveis explicações apareceram neste contexto. Albrecht von Haller (1763), considerou que a contração da pupila diminuiria os círculos borrados suficientemente para explicar o fenômeno, um mecanismo semelhante a câmera obscura presente em alguns animais. Alguns autores sugeriram que $o$ alongamento do globo ocular causado pela contração dos músculos extra-oculares seria responsável pela acomodação. A teoria original de Kepler (1611) que fazia referência a alterações no foco de visão obtidas com o movimento ânteroposterior do cristalino (como ocorre em alguns peixes) recebeu suporte de outros investigadores, até ser demons-

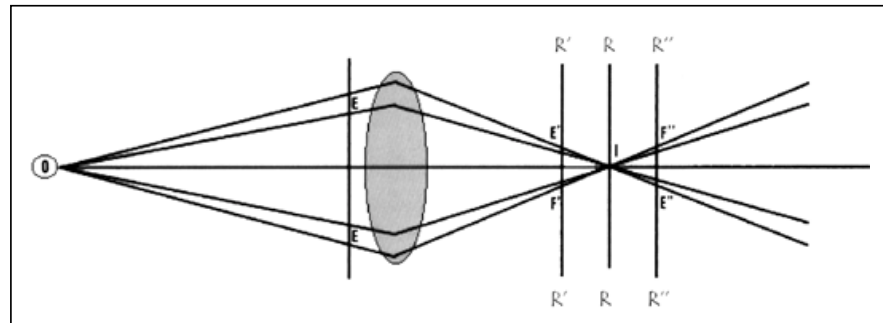

Fig. 2 - Desenho esquemático mostrando o experimento de Scheiner (1619). Se o cartão for perfurado nos pontos $\mathrm{EeE}$, (ou se 2 aberturas forem criadas no cartão nos pontos $\mathrm{E} \mathrm{e} E$ ) o objeto, $O$, estará focalizado no plano, $R$, no ponto I, onde 1 imagem aparecerá. No entanto, se os planos estiverem localizados em R' ou R', 2 imagens aparecerão (E'F' e E' $F$ '). trado que tal movimento (em torno de $10 \mathrm{~mm}$ ) seria impossível de se obter, inviabilizando esta teoria. A possibilidade restante, que a acomodação estaria relacionada a mudanças na forma do cristalino, foi sugerida precocemente por Descartes (1677). Muito tempo depois, Helmholtz ${ }^{3}$ (1853-1856) foi capaz de demonstrar que o ato de acomodação provido pelo músculo ciliar era acompanhado por um incremento na curvatura de ambas as faces do cristalino levando a um aumento na sua espessura. A histologia do segmento anterior e do músculo ciliar do olho humano está revista na figura 3 (A e B).

Em 1965, o "American Committee on Optics and Visual Physiology" adotou a frase: "Put Helmholtz back into Ophthalmology". Hermann von Helmholtz (1821-1894) formado em

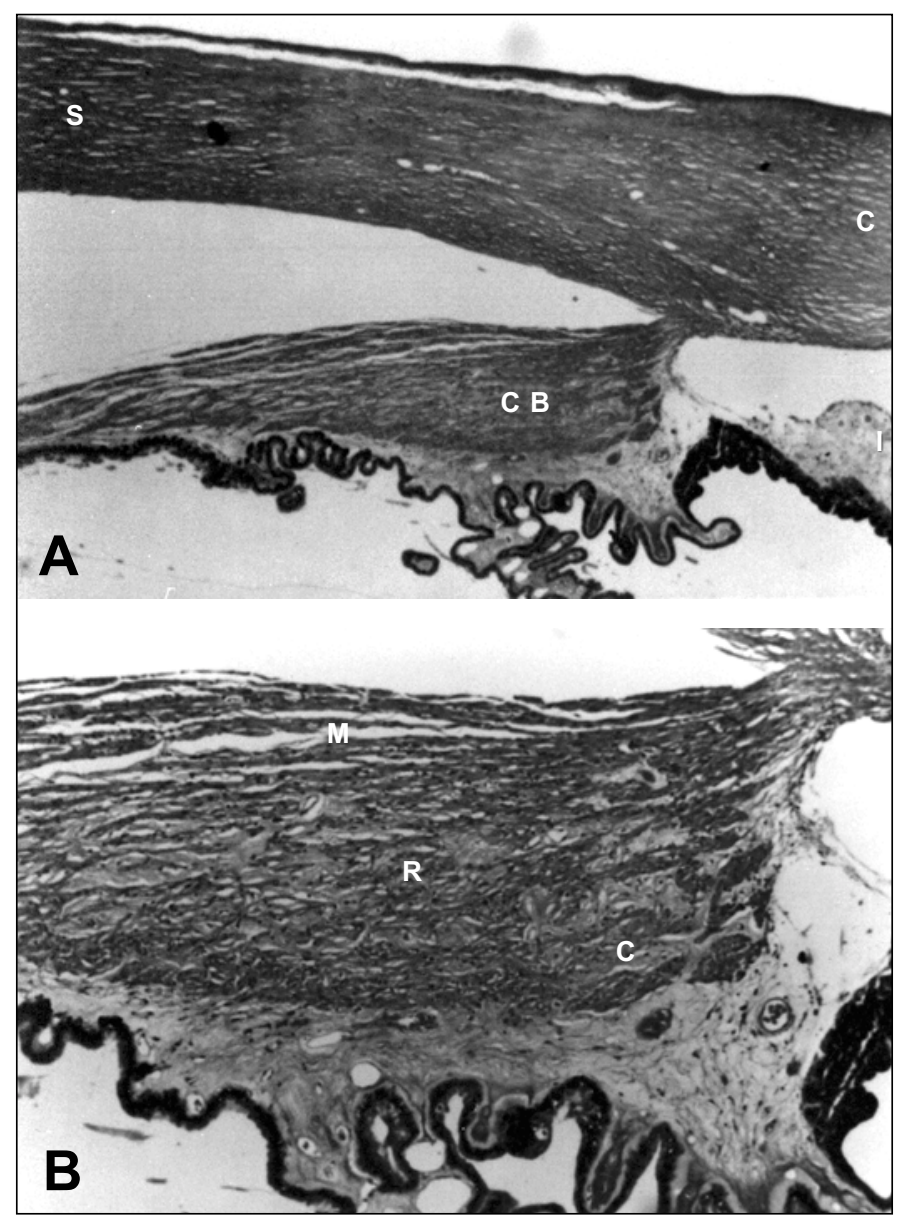

Fig. 3 - Microfotografia de um globo ocular obtido "post-mortem" demonstrando o segmento anterior. Estas secções histológicas estão coradas com Trichromo Masson que identificam as fibras colágenas em azul e as fibras musculares lisas em vermelho; A. Cornea (C), esclera (S), iris (I) e corpo ciliar (CB) podem ser identificados. $O$ músculo ciliar se estende do esporão escleral até a coróide, embora algumas de suas fibras estejam confinadas na pars plicata. Os processos ciliares e a superfície interna do corpo ciliar estão revestidas com duas camadas de epitélio, a mais interna contém pigmentos de melanina (Tricromo Masson, magnificação original $X$ 200); B. Mesma secção em maior magnificação mostrando o corpo ciliar. O músculo ciliar é tradicionalmente dividido em três partes. A mais externa próximo a esclera é a porção meridional (M). As fibras mais internas próximo aos processos ciliares constituem a porção circular (C), e a porção radial (R) localiza-se entre as porções meridional e circular. 
física, tornou-se professor de fisiologia e física, dedicando toda sua vida ao estudo da fisiologia óptica. Ele observou em 1855 que o centro do cristalino aumentava de espessura durante a acomodação. Baseado nesta observação, ele afirmou que quando o olho acomoda, o músculo ciliar contrai reduzindo a tensão zonular levando assim ao aumento do espaço entre o corpo ciliar e o equador do cristalino. Esta diminuição de forças aplicada no equador do cristalino permite que sua cápsula elástica contraia, causando um aumento do diâmetro antero-posterior do cristalino e um aumento do seu poder óptico. Então, o ato de acomodação deve resultar de uma contração do músculo ciliar que reduz o diâmetro do corpo ciliar e relaxa a tensão zonular. Isto permite que cristalinos jovens retomem suas formas originais de curvaturas acentuadas e poder óptico elevado para focalizar objetos próximos sobre a retina. Quando a acomodação cessa, o músculo ciliar relaxa e retorna a sua configuração "desacomodada", a tensão zonular é novamente aumentada e o cristalino é tracionado no equador aumentando assim sua distância focal ${ }^{3}$. O movimento do equador do cristalino é por isso em direção oposta a esclera durante a acomodação (Fig. 4A) e em direção a ela quando do relaxamento do músculo ciliar. Embora a influência da cápsula na determinação da forma do cristalino seja indubitável, a teoria de Helmholtz não poderia permanecer em sua forma original, desde que ela não explica a forma assumida pela superfície anterior do cristalino. Muitos anos depois, Fincham ${ }^{4}$ sugeriu que a forma peculiar do cristalino é devida a sua estrutura capsular. Esta é muito mais espessa na frente do que atrás e as porções anterior e posterior são mais espessas lateralmente do que nos pólos, justamente dentro da inserção das fibras zonulares. As variações de espessura em diferentes partes da cápsula sugere que, o aplanamento do cristalino ocorreria preferencialmente na periferia, onde a cápsula é mais espessa e resistente, havendo um abaulamento da região axial onde é mais fraca. No polo posterior a cápsula é muito fina, e neste ponto ocorre o encurvamento máximo mesmo no estado de desacomodação. É esta diferença de espessura da parte central e lateral da cápsula anterior que
Fincham acredita ser responsável pela forma hiperbólica da superfície anterior do cristalino durante a acomodação.

Durante muitos anos, houve um consenso nas opiniões a respeito do mecanismo de acomodação proveniente da teoria de Helmholtz. Entretanto, Schachar e colaboradores ${ }^{6}$ recentemente propuseram um mecanismo de acomodação alternativo para os primatas que é similar a teoria originalmente proposta por Tscherning ${ }^{7}$. Ambas teorias ${ }^{7-12}$ afirmam que a zônula equatorial se insere no músculo ciliar anterior, na base da íris e que as zônulas anterior e posterior se inserem na porção posterior do músculo ciliar. Schachar e Anderson ${ }^{12}$ alegam que durante a contração do músculo ciliar, através da ação das fibras radiais e longitudinais, a porção anterior do músculo ciliar se desloca em direção a esclera na base da íris. Este movimento aumenta a tensão na zônula equatorial enquanto relaxa a tensão nas fibras zonulares anterior e posterior. Schachar acredita que as forças aplicadas desta maneira tracionariam o equador do cristalino em direção a esclera durante a acomodação e, juntamente com o relaxamento das fibras zonulares anterior e posterior, haveria um aplanamento da periferia do cristalino enquanto o centro aumenta sua curvatura. O movimento do equador do cristalino é então em direção a esclera durante a acomodação (Fig. 4B) e em direção oposta a ela quando do relaxamento do músculo ciliar. Do ponto de vista teórico, o tracionamento do equador do cristalino poderia causar um aumento das curvaturas centrais, dependendo das propriedades viscoelásticas do mesmo. A teoria de Schachar entretanto difere daquela de Tscherning porque ela não depende do vítreo para explicar as mudanças de forma do cristalino que ocorrem durante a acomodação. ${ }^{13} \mathrm{~A}$ base da teoria de Schachar é que o diâmetro equatorial aumenta durante a acomodação. Entretanto, um grupo de estudos recentes demonstraram, usando métodos de imagem, que o diâmetro do cristalino diminui durante a acomodação, como descreve a literatura clássica e contrário a contenção de Schachar (Fig. 5 A-B). Wilson ${ }^{14}$ demonstrou, usando transiluminação escleral com luz infravermelha em olhos humanos albinos, que o equador do cristalino se movimenta em direção oposta a esclera

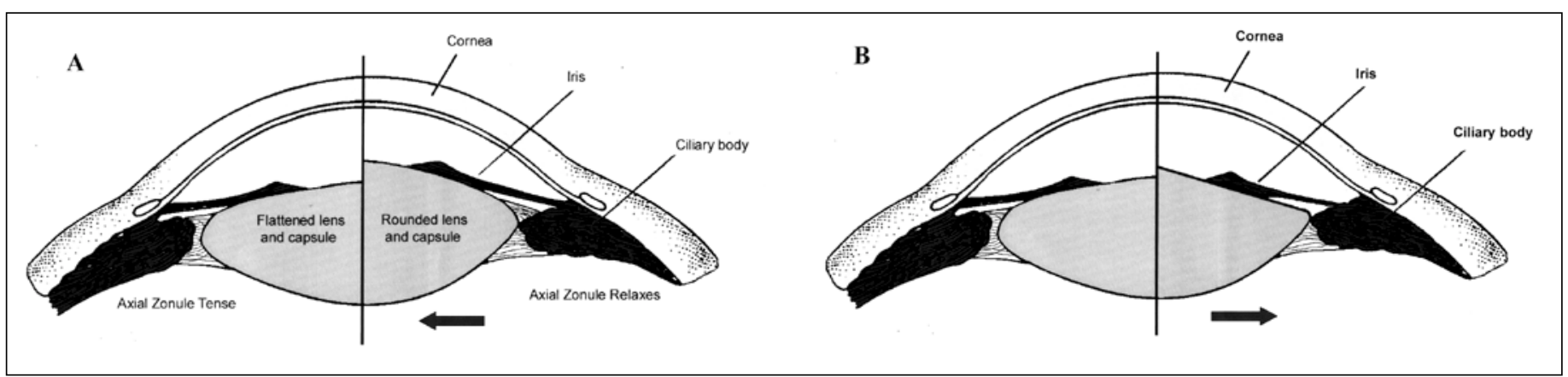

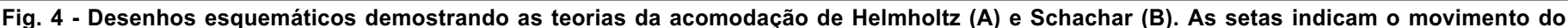

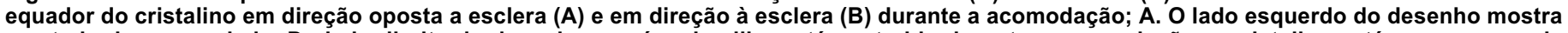

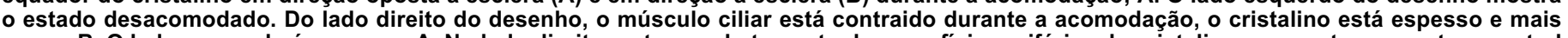

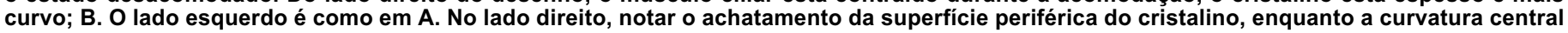
anterior aumenta. 


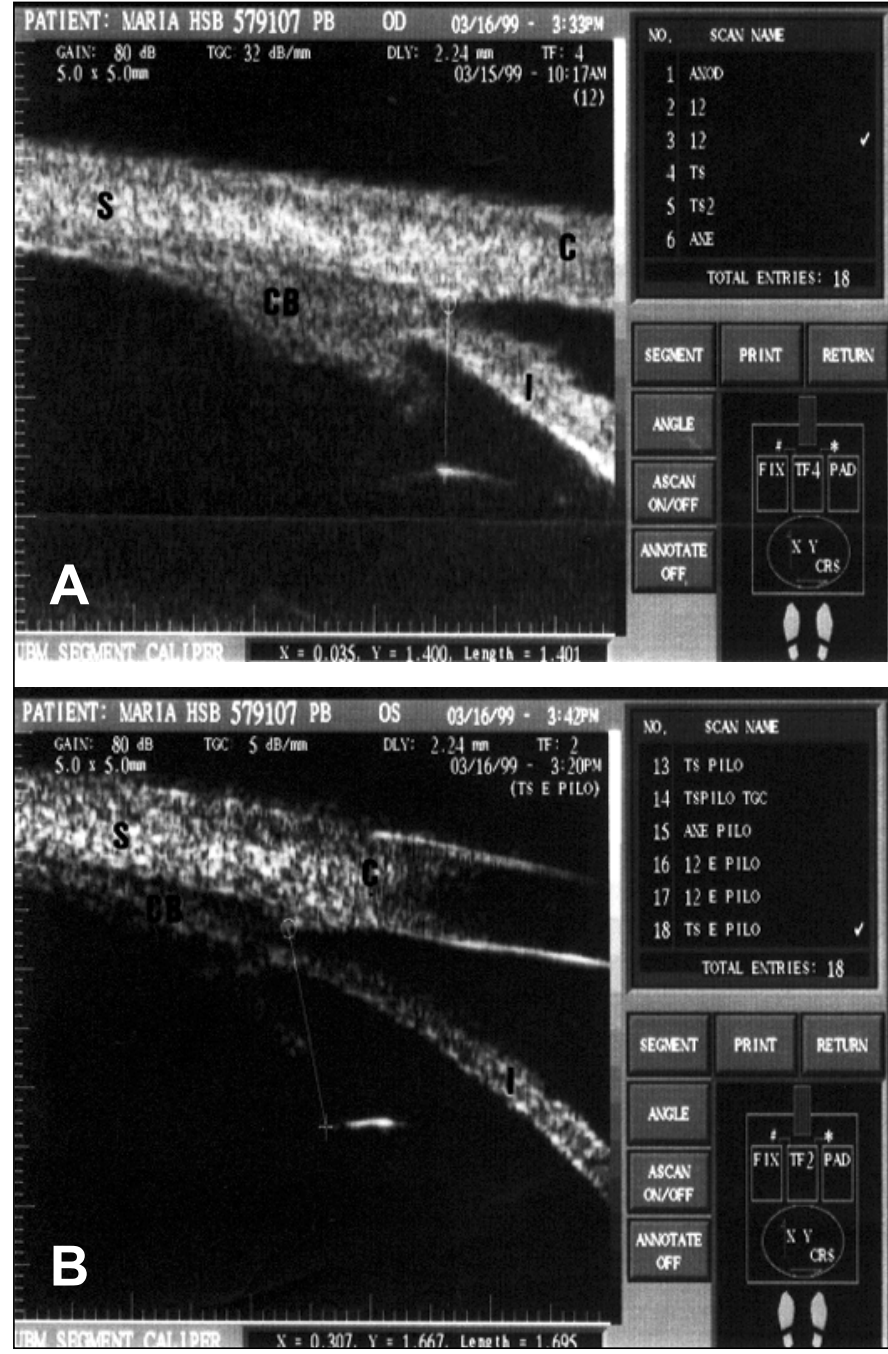

Fig. 5 - Imagens de biomicroscopia ultrassônica (BUS) do equador do cristalino humano (setas) em relação ao esporão escleral (asterisco) durante o estado desacomodado induzido por tropicamida $(1 \%)$ e o estado acomodado induzido por pilocarpina $(2 \%)$. A sonda encontrase posicionada sobre a região temporal do corpo ciliar. Cornea (C), esclera (S), íris (I) e corpo ciliar (CB) podem ser identificados em ambas as figuras; A. No estado desacomodado a distância entre o equador do cristalino e o esporão escleral é de $1,401 \mathrm{~mm}$; B. No estado acomodado a distância entre o equador do cristalino e o esporão escleral é de $1,695 \mathrm{~mm}$.

durante a acomodação. Glasser and Kaufman ${ }^{13}$ estudaram os movimentos do equador do cristalino e do corpo ciliar usando biomicroscopia ultrasônica e goniovideografia durante a acomodação e desacomodação. Eles encontraram que, apesar dos movimentos oculares sistemáticos devido a estimulação elétrica e não sistemáticos devido a estimulação farmacológica, em todos os instantes o corpo ciliar e o equador do cristalino moveram-se em direção oposta a esclera durante a acomodação. Outro estudo conduzido por Glasser and Campbell ${ }^{15}$ demonstraram que o estiramento mecânico da zônula do cristalino humano aumenta o comprimento de foco, de acordo com a teoria clássica de Helmholtz. Além disto, não existe nenhuma confirmação da descrição anatômica da região ciliar, do mecanismo acomodativo ou causas da presbiopia descrita por Schachar. O movimento posterior direcionado externamente da porção anterior do músculo ciliar em direção à esclera, como foi sugerido por este autor através de análise histológica, não pôde ser observado por métodos de imagens ${ }^{13}$. Também, as descrições das inserções zonulares conflita com as evidências observadas pelas análises histológicas e de microscopia eletrônica de varredura ${ }^{15,16}$. Não há inserção de fibras zonulares equatoriais ou nenhuma outra fibra zonular na base da íris e no músculo ciliar anterior (Fig. 6A e B). As fibras destinadas a porção anterior e equatorial da cápsula foram demonstradas estarem fortemente aderidas aos processos ciliares. Elas partem acompanhadas com as zônulas posteriores continuando em um curso retilíneo até a inserção. Ambas as zônulas anteriores e posteriores saem das pars plicata como fitas, estendendo-se paralelas aos processos ciliares. As poucas zônulas estendendo-se ao equador do cristalino originam-se das partes centrais dos processos ou
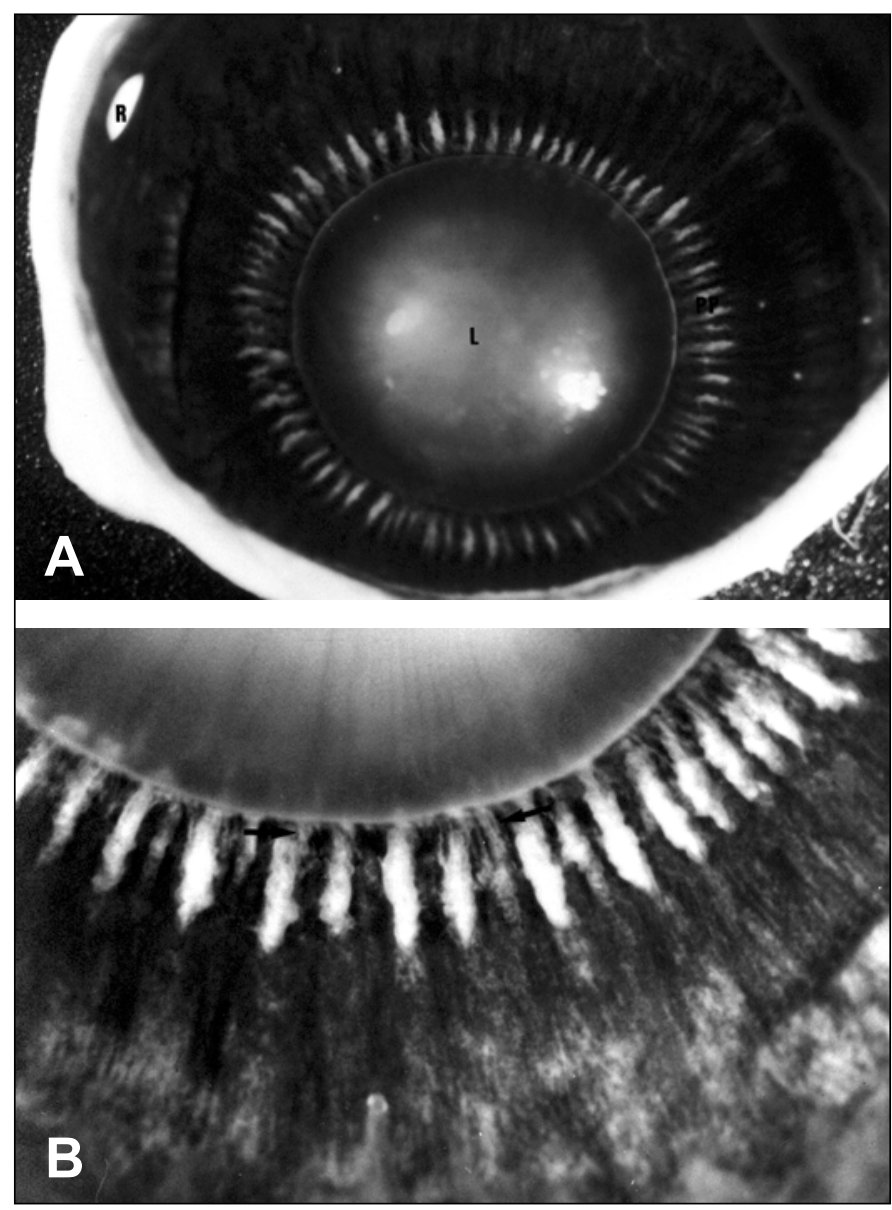

Fig. 6 - Fotografia tirada do microscópio cirúrgico de um globo ocular obtido "post-mortem" depois de seccionado no equador, mostrando a superfície interna do segmento anterior com ângulo de visão posterior; A. O cristalino (L) está no centro, circundado por uma série de linhas radiais que são os processos ciliares, a pars plicata (PP). Este último está delimitado pela pars plana, que se termina com bordos irregulares na ora serrata, onde se inicia a retina $(R)$; $B$. Mesma imagem com magnificação maior. Note as zônulas (setas) ancorando o cristalino à pars plicata do corpo ciliar. 
dos vales e geralmente derivam das faixas de zônulas anteriores e posteriores ${ }^{5}$.

\section{Presbiopia}

A presbiopia é a mais comum das desordens refrativas da vida adulta, estando relacionada a diminuição da amplitude de acomodação ${ }^{17}$. Em indivíduos emétropes e hipermétropes, a presbiopia se manifesta em torno dos 40 anos, havendo necessidade de óculos para leitura ou lentes de contato. Embora indivíduos míopes se beneficiem nesta idade, podendo as vezes ler sem auxílio óptico, suas amplitudes de acomodação também diminuem com a idade de maneira mais ou menos regular. Os sintomas começam com uma dificuldade em focalizar objetos próximos e avançam com cansaço visual durante a leitura, às vezes acompanhado de ardência ocular e lacrimejamento. Letras pequenas tornam-se ilegíveis na distância habitual levando ao borramento da imagem. Os sintomas são intensificados sob luz inadequada e tendem a ser piores ao final do dia ${ }^{18}$.

Apesar dos custos anuais acarretados por este problema (National Advisory Eye Council, 1983), a(s) causa(s) básica(s) da presbiopia ainda resta(m) inexplicada(s). Vários estudos baseados na teoria de Helmholtz tentaram explicar a perda da acomodação em indivíduos idosos. Quando se consideram várias possibilidades, qualquer teoria proposta deve levar em consideração o conhecido declínio da habilidade ocular de alterar o seu foco com a idade. Alguns estudos sugerem uma perda da elasticidade capsular e zonular com a idade, por isto, quando a zônula está relaxada o cristalino não é capaz de alterar sua forma ${ }^{19}$. Existem alguns trabalhos que sugerem uma atrofia do músculo ciliar com a idade. ${ }^{20}$ Existe também outros que fazem referência à uma deposição contínua de fibras sobre o cristalino tornando-o mais compacto com pouca maleabilidade. O fator mais importante para a perda da acomodação poderia ser também o aumento do grau de dureza do cristalino envelhecido, levando a uma inabilidade de responder ao estímulo acomodativo ${ }^{21}$ Em geral, o conjunto de teorias proposta para se explicar as alterações que podem ocorrer no olho resultando na presbiopia são agrupadas em três categorias: teorias baseadas no cristalino e cápsula, que consideram as alterações na elasticidade e complacência do cristalino e da cápsula; teorias extralenticulares, que consideram as alterações no músculo ciliar e coróide; e teorias geométricas, que consideram as alterações da inserção zonular no cristalino ${ }^{15}$.

Fincham ${ }^{22}$ adicionou novos achados que davam suporte a teoria acomodativa de Helmholtz, oferecendo evidências de que a presbiopia era causada pela inabilidade da cápsula em moldar a substância endurecida do cristalino para a forma acomodada. Fischer ${ }^{23}$ e Pau and Kranz ${ }^{24}$ também apoiaram a teoria da presbiopia de Fincham atribuindo a perda da capacidade de acomodação às alterações das propriedades elásticas do cristalino. Além disto, Fischer ${ }^{25}$ encontrou que a elasticidade capsular diminui pela metade entre a juventude e os 60 anos de idade. Baseado nestas evidências, nós podemos presumir que a redução da elasticidade capsular sozinha não pode explicar a presbiopia, somente diminuindo a capacidade de alterar a curvatura do cristalino. Avaliando-se a pressão de moldeamento capsular vs estiramento lenticular, Fischer ${ }^{23}$ concluiu que a diminuição da amplitude deve estar relacionada a redução da elasticidade capsular, alterações da elasticidade da substância do cristalino, e aplanamento do mesmo. Estes achados apoiam a teoria de Fincham da presbiopia porque uma menor elasticidade capsular exerceria menos força na substância endurecida do cristalino idoso. Quando o cristalino é desencapsulado (em cobaias jovens), ele torna-se fino e aplanado ${ }^{2}$. Estas observações sugerem que a substância do cristalino tende a restaurar as forças, mantendo-o no estado desacomodado. Estas forças são em contrapartida antagonizadas pela elasticidade capsular. Weale ${ }^{26}$ sugeriu que em olhos jovens, as forças elásticas são dominantes, enquanto as forças restauradoras da substância do cristalino predominam na presbiopia.

As teorias baseadas no cristalino e cápsula aceitam uma evidência indireta de que o músculo ciliar é capaz de prover a mesma magnitude de força em olhos jovens e présbitas. Medidas através de ciclografia de impedância demonstraram que a contração do músculo ciliar mantém-se estável até a idade de 60 anos, dando suporte a estas teorias ${ }^{27}$. Entretanto, estes achados chegaram a ser criticados devido à incerteza do que exatamente este exame seria capaz de medir. As dúvidas resultam em parte da observação de que um determinado estímulo acomodativo não produz consistentemente uma mesma impedância ${ }^{28}$. Também, em macacos rhesus que possuem um sistema acomodativo similar ao dos humanos e que desenvolvem presbiopia em uma escala de tempo relativo ao envelhecimento ${ }^{29}$, a habilidade do músculo ciliar de alterar a sua configuração em resposta a drogas ou estimulação elétrica do núcleo de Edinger-Westphal claramente declina com a idade ${ }^{30-32}$. Estes resultados potencialmente controversos podem sugerir uma possível perda da função do músculo ciliar concorrente com o desenvolvimento da presbiopia. Estando de acordo com as teorias extralenticulares, Fuchs ${ }^{2}$ pioneiramente relatou que a cicloplegia é mais efetiva em olhos jovens do que em idosos, e Duane ${ }^{33}$ demonstrou que que a taxa de cicloplegia é mais rápida em présbitas jovens do que indivíduos não présbitas. Além disso, se o desgaste do músculo ciliar fosse significante, o seu exercício vigoroso (hipermetropia, leitura de perto prolongada) poderia reverter a presbiopia e não existe evidência de que isto ocorra ${ }^{15,34}$.

Brown ${ }^{35}$ sugeriu que a presbiopia está associada com a liquefação do vítreo, desde que os dois processos ocorrem aproximadamente na mesma época da vida. Entretanto, esta teoria não explica o porque do declínio da amplitude de acomodação começar as vezes tão cedo na vida ${ }^{36}$. Outra possibilidade poderia dar suporte ao conceito de teorias geométricas, baseado na observação de que a localização das inserções zonulo-lenticulares relativo ao equador do cristalino e do músculo ciliar mudam com a idade, sabendo-se que o cris- 
talino aumenta de tamanho ${ }^{37}$. Este tipo de alteração na geometria do segmento anterior resultaria em uma maior retenção das forças zonulares aplicadas no cristalino durante a contração do músculo ciliar, sem necessariamente requerer outras mudanças nas propriedades do segmento anterior ${ }^{38-40}$. Estas observações, também relatadas por Brown ${ }^{41}$ de um aumento do cristalino com a idade alterando suas curvaturas e por Farnsworth and Shyne ${ }^{37}$ de uma mudança das inserções zonulares no cristalino, levaram a sugestão de que fatores distintos podem interagir e contribuir para a falência de um cristalino envelhecido para acomodar, permanecendo então em um estado desacomodado.

Mais recentemente, a presbiopia foi descrita como sendo uma desordem geométrica secundária somente às alterações do tamanho e volume do cristalino. Schachar ${ }^{6}$ propôs que a tensão zonular aumenta durante a acomodação em indivíduos jovens, em contraste com a teoria clássica de Helmholtz, descrita acima. Ainda com relação a esta nova teoria, Schachar e cols. ${ }^{8}$ acreditam que a presbiopia resulta de uma diminuição da tensão zonular causada pelo crescimento normal do cristalino com a idade. Este possui uma origem ectodérmica e continua a crescer durante toda a vida, tendo o seu diâmetro equatorial aumentado na ordem de $0,02 \mathrm{~mm} / \mathrm{ano}$. Entretanto, à exceção da miopia progressiva, as dimensões da esclera não mudam significamente depois dos 13 anos de idade. De acordo com o autor, a distância entre o músculo ciliar e o equador do cristalino diminui durante a vida. Como conseqüência, as forças efetivas que o músculo ciliar poderia exercer no equador do cristalino ficaria reduzida de maneira linear com a idade. A amplitude de acomodação diminui linearmente com a idade resultando na presbiopia e isto seria uma conseqüência do crescimento normal do cristalino ${ }^{8-12}$. De acordo com Schachar ${ }^{10}$, a expansão cirúrgica da esclera em torno do corpo ciliar pode restaurar a acomodação, sendo então uma solução para a presbiopia. A cirurgia de expansão escleral envolve a

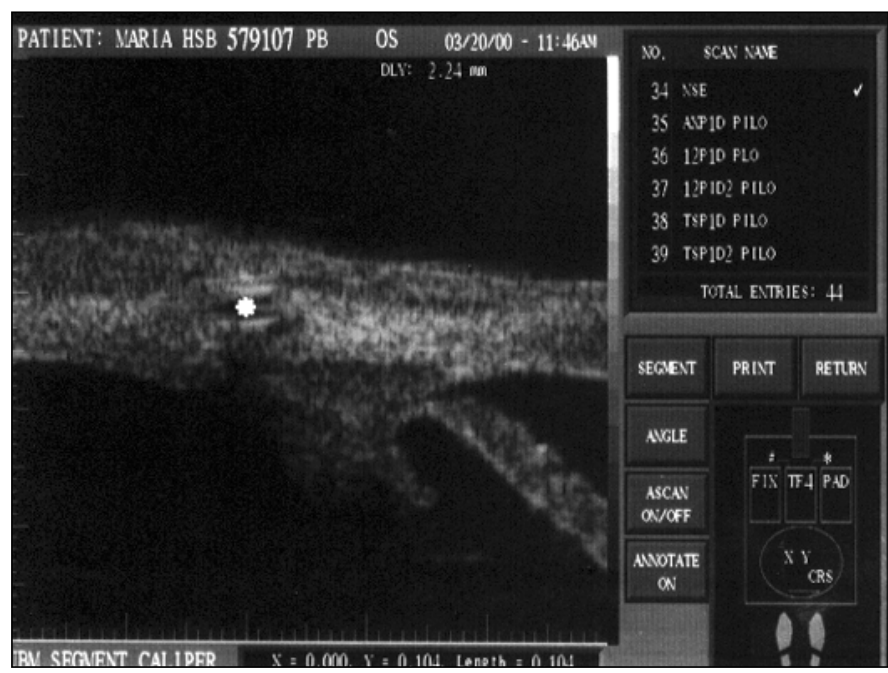

Fig. 7 - Imagem de biomicroscopia ultrassônica (BUS) de uma banda expansora escleral (asterisco) implantada na esclera sobre o corpo ciliar. implantação de anéis de plástico ou arcos (semi-anéis) de plásticos (bandas expansoras esclerais) na esclera que circunda o corpo ciliar, aumentando assim o espaço entre o corpo ciliar e o equador do cristalino (Fig. 7). Em quatro pacientes operados no nosso Departamento de Oftalmologia, nós encontramos que a visão para perto melhorou em dois pacientes, enquanto a amplitude de acomodação permaneceu estável em todos os casos após a cirurgia. Baseado nestes achados também relatados por outros autores ${ }^{13,42}$, nós podemos presumir que a eficácia da cirurgia de expansão escleral no tratamento da presbiopia não foi completamente determinada e existem algumas evidências de que a melhora obtida em alguns pacientes pode representar apenas uma conseqüência de aberrações lenticulares, resultando num sistema óptico multifocal, ao invés de uma verdadeira acomodação.

Este conceito de perda da acomodação com a idade, relacionada a diminuição da tensão zonular resultante do crescimento contínuo do cristalino durante a vida, ao invés de esclerose cristaliniana, foi também descrito por Weale ${ }^{26} \mathrm{e}$ Bito e Miranda ${ }^{43}$. Tscherning ${ }^{7}$ também postulou que haveria um aumento da tensão zonular durante a acomodação, como foi descrito por Schachar e mencionado acima. Entretanto, ele imaginou que o equador do cristalino se moveria posteriormente durante a acomodação, atribuindo ele a presbiopia ao alargamento do núcleo. Esta contribuição do cristalino no desenvolvimento da presbiopia foi sugerida também devido a mudanças na elasticidade capsular e na substância. O contínuo crescimento equatorial do cristalino referido por Schachar e outros autores permanece sem respaldo experimental não sendo universalmente aceito, devido ao fato de que Farnsworth e Shyne ${ }^{37}$ terem demonstrado que a distância do corpo ciliar à inserção zonular sobre o cristalino não se altera com a idade. Além disto, Weale e Bito e Miranda não demonstraram nenhuma evidência experimental que pudesse reforçar suas afirmações de que a esclerose do cristalino não ocorre, e suas contenções não são consistentes com achados experimentais subsequentes ${ }^{23,25}$.

Embora muitas teorias sobre as causas da presbiopia terem invocado alterações na constituição do cristalino, relativamente poucos estudos mediram diretamente as alterações das propriedades ópticas do mesmo com a idade. Glasser and Campbell ${ }^{15}$ usaram uma técnica de Laser de Varredura para medir as propriedades ópticas do cristalino em 27 olhos humanos entre 10 e 87 anos de idade. Eles encontraram que o cristalino após os 58 anos de idade não mudaria sua distância focal, quando do aumento ou diminuição de forças aplicadas sobre o complexo zonular do corpo ciliar. A teoria de Schachar pressupõe que a presbiopia é devido puramente ao crescimento do cristalino, que se mantém maleável durante toda a vida. Ao contrário da teoria de Schachar, o estudo de Glasser e Campbell fortemente apoia as clássicas teorias da presbiopia baseado no princípio de que o cristalino se torna enrijecido com a idade.

Em conclusão, os olhos envelhecem na sua estrutura e 
função e, embora isto seja parte do processo natural da vida, a presbiopia é considerada ainda nos dias de hoje uma condição irreversível. Entretanto, seu diagnóstico e tratamento com óculos são o mais comum, se não o mais simples dos problemas refrativos. Nós vimos que nenhum dos experimentos que tentaram explicar a perda da acomodação com a idade foi crucialmente conclusivo e alguns dos resultados poderiam ter sido influenciados pelo treinamento dos pacientes. Quando se revisa as diversas teorias propostas desde longa data, deve-se admitir que a disputa está ainda sem conclusão definitiva, mas os mecanismos do cristalino aparecem como o mais importante fator na determinação da presbiopia. Até os dias de hoje, Helmholtz criou a mais aceita teoria do mecanismo físico da acomodação. Entretanto, novos estudos ainda são necessários para dispersar várias noções incorretas sobre o desenvolvimento da presbiopia, identificando quais os fatores relacionados a idade que contribuem para a perda da capacidade de acomodação.

\section{SUMMARY}

Presbyopia is one of the earliest universal signs of aging and the basic pathophysiology involved in its development has been a matter of controversy for centuries. This article discusses many aspects of presbyopia by reviewing the literature on the multitude of age-related changes that occur in the eye.

\section{Keywords: Accommodation; Presbyopia.}

\section{REFERÊNCIAS}

1. Michaels DD. Accommodation, Vergences, and Heterophorias. In: Michaels DD, eds. Visual Optics and Refraction, 3rd ed. St. Louis: C.V. Mosby, 1985: Chap. XVIII.

2. Duke-Elder S. Adjustments to the optical system: accommodation. In: DukeElder S, eds. System of Ophthalmology: Ophthalmic Optics and Refraction, St. Louis: C.V. Mosby, 1970; Vol. V, Chap. IV.

3. Von Helmholtz H. Physiological Optics. New York: Dover, 1962; vol.I, 143$172,375-415$.

4. Fincham EF. The mechanism of accommodation. $\mathrm{Br} \mathrm{J}$ Ophthalmol 1937;8(Suppl):5-80.

5. Last RJ. The eyeball. In: Wolff E, eds. The Anatomy of the Eye and Orbit, 6th ed. Philadelphia, Pa: W.B. Saunders, 1968; Chap. II.

6. Schachar RA, Cudmore DP, Black TD. Experimental support for Schachar's hypothesis of accommodation. Ann Ophthalmol 1993;25:404-9.

7. Tscherning M. Physiologic Optics: Dioptrics of the Eye, Functions of the Retina, Ocular Movements, and Binocular Vision, 2nd ed. Philadelphia: Keystone, 1904;160-89.

8. Schachar RA, Black TD, Kash RL, Cudmore DP, Schanzlin DJ. The mechanism of accommodation and presbyopia in the primate. Ann Ophthalmol 1995;27:58-67.

9. Schachar RA, Cudmore DP, Torti R, Black TD, Huang T. A physical model demonstrating Schachar's hypothesis of accommodation. Ann Ophthalmol 1994;26:4-9.

10. Schachar RA. Cause and treatment of presbyopia with a method for increasing the amplitude of accommodation. Ann Ophthalmol 1992;24:445-52.

11. Schachar RA, Tello C, Cudmore DP, Liebmann JM, Black TD, Ritch R. In vivo increase of the human lens equatorial diameter during accommodation. Am J Physiol 1996;271:670-6.

12. Schachar RA, Anderson DA. The mechanism of ciliary muscle function. Ann Ophthalmol 1995;27:126-32.

13. Glasser A, Kaufman PL. The mechanism of accommodation in primates. Ophthalmology 1999;106:863-72.

14. Wilson RS. Does the lens diameter increase or decrease during accommodation? Human accommodation studies: a new technique using infrared retro-illumination video photography and pixel unit measurements. Trans Am Ophthalmol Soc 1997;95:261-70.

15. Glasser A, Campbell MCW. Presbyopia and the optical changes in the human crystalline lens with age. Vision Res 1998;38:209-29.

16. Rohen JW. Scanning electron microscopic studies of the zonular apparatus in human and monkey eyes. Invest Ophthalmol Vis Sci 1979;18:133-44.

17. Milder B, Rubin ML. Progressive power lenses. Surv Ophthalmol 1987;32:189-98.

18. Eichenbaum JW, Simmons DH, Velazquez C. The correction of presbyopia: a prospective study. Ann Ophthalmol 1999;31:81-4.

19. Brown N. The change in shape and internal form of the lens of the eye on accommodation. Exp Eye Res 1973;15:441-59.

20. Fischer RF. The force of contraction of the human ciliary muscle during accommodation. J Physiol 1977;270:51-74.

21. Van Heyningen R. What happens to the human lens in cataract? Sci Am 1975;233:70-2,77-81.

22. Fincham EF. The mechanism of accommodation. Br J Ophthalmol 1937;8:5-80.

23. Fisher RF. Elastic constants of the human lens. J Physiol 1971;212:147-80.

24. Pau H, Kranz J. The increasing sclerosis of the human lens with age and its relevance to accommodation and presbyopia. Graefes Arch Clin Exp Ophthalmol 1991;229:294-6.

25. Fisher RF. Presbyopia and the changes with age in the human crystalline lens. J Physiology 1973;228:765-79.

26. Weale RA. Presbyopia. Br J Ophthalmol 1962;46:660-8.

27. Swegmark G. Studies with impedance cyclography on human ocular accommodation at different ages. Acta Ophthalmologica 1969;46:1186-206.

28. Sladin JJ, Stark L. Presbyopia: New evidence from impedance cyclography supporting the Hess-Gullstrand theory. Vision Research 1975;15:537-41.

29. Bito LZ, DeRousseau, CJ, Kaufman PL, Bito JW. Age-dependent loss of accommodative amplitude in rhesus monkeys: an animal model for presbyopia. Invest Ophthalmol Vis Sci 1982;23:23-31.

30. Neider MW, Crawford K, True B, Kaufman PL Bito LZ. Functional studies of accommodation and presbyopia in rhesus monkeys. Invest Ophthalmol Vis Sci $1986 ; 27($ S):81.

31. Bito LZ, Kaufman PL, Neider M, Miranda OC, Antal P. The dynamics of accommodation (ciliary muscle contraction, zonular relaxation and lenticular deformation) as a function of stimulus strength and age in iridectomized rhesus eyes. Invest Ophthalmol Vis Sci 1987;28(S):318.

32. Lutjen-Drecoll E, Tamm MD, Kaufman PL. Age-related loss of morphologic responses to pilocarpine in rhesus monkey ciliary muscle. Arch Ophthalmol 1988;106:1591-8.

33. Duane A. Normal values of the accommodation at all ages. JAMA 1912;59:1010-3.

34. Koretz JF, Kaufman PL, Neider MW, Goeckner PA. Accommodation and presbyopia in the human eye-aging of the anterior segment. Vision Res 1989;29:1685-92.

35. Brown NP. In the human lens in relation to cataract. CIBA Foundation Symposium 1973;19:65-78.

36. Duane A. Studies in monocular and binocular accommodation with their clinical applications. Am J Ophthalmol 1922;5:867-77.

37. Farnsworth PN, Shyne SE. Anterior zonular shifts with age. Exp Eye Res 1979;28:291-7.

38. Handelman GH, Koretz JF. A mathematical representation of lens accommodation. Vision Res 1982;22:924-7.

39. Koretz JF, Handelman GH. A model of the accommodative mechanism in the human eye. Vision Res 1982;22:917-24.

40. Koretz JF, Handelman GH. A model for accommodation in the young human eye. Vision Res 1983;23:1679-86.

41. Brown NP. The change in lens curvature with age. Exp Eye Res 1974;19:175-83.

42. Mathews S. Scleral expansion surgery does not restore accommodation in human presbyopia. Ophthalmology 1999;106:873-7.

43. Bito LZ, Miranda OC. Accommodation and presbyopia. In Reinecke RD (Ed.), Ophthalmology annual. New York: Raven Press. 1989;103-28. 